Research Article

\title{
Lognormal Distribution Function for Describing Seepage Damage Process of Single-Cracked Rock
}

\author{
Xinyu Liu $\mathbb{D}^{1,2,3}$ Zhende Zhu, $^{2,3}$ Aihua Liu, ${ }^{4}$ and Yuan Tian ${ }^{2,3}$ \\ ${ }^{1}$ College of Civil Engineering and Architecture, Zhejiang University of Water Resources and Electric Power, \\ Hangzhou 310018, China \\ ${ }^{2}$ Key Laboratory of Ministry of Education for Geomechanics and Embankment Engineering, Hohai University, \\ Nanjing 210098, China \\ ${ }^{3}$ Jiangsu Research Center for Geotechnical Engineering, Hohai University, Nanjing 210098, China \\ ${ }^{4}$ College of Water Conservancy and Civil Engineering, South China Agricultural University, Guangzhou 510642, China
}

Correspondence should be addressed to Xinyu Liu; liuxy267@hhu.edu.cn

Received 17 April 2020; Revised 10 June 2020; Accepted 24 June 2020; Published 29 July 2020

Academic Editor: Chiara Bedon

Copyright (c) 2020 Xinyu Liu et al. This is an open access article distributed under the Creative Commons Attribution License, which permits unrestricted use, distribution, and reproduction in any medium, provided the original work is properly cited.

The precondition of rock stress and deformation analysis is a reasonable rock constitutive model. Most of the previous studies have described the heterogeneous microdamage by Weibull distribution or normal distribution. However, both of them have limitations. Therefore, this paper intends to use the lognormal distribution as the probability distribution model of rock microunit strength. Based on the tensile failure of the single-fractured rock under the hydrodynamic force, the maximum tensile strain failure criterion is used as the distribution parameter of rock microunit strength. And, considering the multiphase properties of the filling fractured rock, the equivalent elastic modulus parameter is adopted in the model. We design a triaxial seepage test for the filled single-fractured rock and analyze the applicability and rationality of the modified lognormal statistical damage model for characterizing the fractured rock by using the test data. According to the comparison of the experimental stress-strain curve and the model stress-strain curve and the analysis of the damage value test curve and the model curve, the rationality of the established statistical damage constitutive model is verified, and the advantages and limitations of the model are proposed.

\section{Introduction}

The precondition of rock stress and deformation analysis is a reasonable rock constitutive model, which is the theoretical basis for stability prediction and evaluation of the surrounding rock in geotechnical engineering and also the key to the development of rock mechanic science. Dougill [1] studied the damage evolution and applied the damage theory to rock mechanics in 1976. Its main content is to study the damage evolution law of damaged materials and the damage theory. At present, there are two main research methods of the damage constitutive model reflecting the whole process of rock deformation and failure. One is based on the phenomenological statistical damage simulation method [2-7] (as shown in Table 1) and the other is based on CT, scanning electron microscopy, optical microscopy, laser holographic interferometry, and numerical modeling methods [8-14], which describe the damage situation of materials by quantitatively describing the damage structure information on the surface or inside of materials. Most of the previous studies have regarded the macrofailure phenomenon as the average effect of microunit destruction and described the heterogeneous microdamage by Weibull distribution or normal distribution, so as to establish a statistical damage model of rock under uniaxial or triaxial compression, describing the damage parameters of the rock and the constitutive relationship curve of the failure process.

However, for brittle materials such as the rock, the Weibull theory cannot reflect the nonlocal characteristics of the damage, and the application of the Weibull theory to brittle materials will inevitably lead to size effect, resulting in a large difference between the theoretical results and the 
TABle 1: Phenomenological statistical damage method.

\begin{tabular}{lccc}
\hline Statistical method & Weibull distribution & Normal distribution & Lognormal distribution \\
\hline & Weibull [2] & Yang et al. [7] & \\
Research achievements & Krajcinovic and Silva [3] & Chen et al. [16] & Zhang et al. [17] \\
& Cao et al. [4] & Cao et al. [6] & \\
& Chen et al. [5] & & \\
\hline
\end{tabular}

experimental results [15]. So far, researchers still pay more attention to the continued research and improvement of this classic theory. At the same time, considering the variables of normal distribution defined on $(-\infty,+\infty)$, if a normal distribution is used, it means that the model parameters may have negative values, while the material properties can only take positive values, which is not consistent with the physical meaning of the parameters themselves, so strictly speaking, it is not suitable for describing the material properties [16].

Based on the investigation of the factors affecting the strength of rock material RVE (representative volume element), Zhang et al. [17] propose that the lognormal distribution has a strict probability theorem as the theoretical basis, which may better reflect the properties of rock materials in real structures.

Therefore, on the basis of previous studies, this paper intends to use the lognormal distribution as the probability distribution model of rock microunit strength. According to the failure characteristics of the cracked rock in the seepagestress field, the strength of the rock microunit is determined by the maximum tensile strain failure criterion. At the same time, considering the multiphase properties of the filling fractured rock, the equivalent elastic modulus parameter is adopted in the model. Finally, for the influence of confining pressure and water pressure, Hooke's law and effective stress principle are used to modify. The statistical constitutive model of the lognormal distribution of seepage damage in the cracked rock is established. In this paper, the advantages and limitations of the model are obtained by comparing the experimental stress-strain curve with the model stress-strain curve. Based on the analysis of the damage variable test curve and the model curve, the rationality of the established statistical damage constitutive model is verified.

\section{Rock Failure}

2.1. Hydraulic Failure Mechanism of Single-Cracked Rock. As shown in Figure 1, the water pressure $p$ acts on the inner side of the crack and the surrounding rock stress $\sigma_{3}$ acts on the far side of the fracture. The force on the crack boundary is $\sigma_{t}$ (rock tensile strength). The failure problem of the singlecracked rock mass can be solved by the Dugdale model.

The rise of groundwater along the fault plane under pressure is called water wedge action. There are two manifestations. One is the splitting failure of rock cracks caused by water pressure. When the surrounding rock is in the state of compressive stress, the water pressure overcomes the surrounding rock stress and the rock tensile strength to induce the crack propagation. The other is the squeezing failure of rock cracks caused by water pressure. When the crack width in the rock mass is large or water-conducting fractures are formed, water pressure squeezes into the rock mass to promote the increase in the crack depth.

Therefore, water pressure enters the cracked rock mass, forming a large pore wall pressure, resulting in the formation of tensile cracks. The tensile strain rate in a certain direction first reaches an allowable value, and finally, the damaged rock in this environment contains more longitudinal tensile cracks.

2.2. Test Design and Results. Scholars carry out some studies on the mechanical properties of seepage in fractured rocks $[18,19]$, but there are few experiments on seepage in fractured rocks considering the filling material. In order to verify the failure mechanism and mode of cracked rock mass under water pressure, we have conducted the triaxial seepage test of single filled cracked rock.

The natural rock mass structure is complex, and the rock samples taken at the site are random and nonrepeatable. When studying the influence of cracks on the rock mass seepage damage, it is difficult to control the variables to obtain effective conclusions. At present, in the indoor seepage test of the filled fractured rock mass, the joints are prefabricated by cutting and splitting and then filled. In this study, the single crack is made in the intact sandstone by cutting. According to the common types of fillings in natural fractured rock masses recorded in the Engineering Geology Site Manual, cement mortar is used to fill the prefabricated cracks to complete the sample.

First, select the complete sandstone rock sample $(\varnothing 50 \mathrm{~mm} \times 100 \mathrm{~mm})$. Then, a cutter is used to cut from one end of the cylinder to form a single slit with a width of $6 \mathrm{~mm}$ and a length of $25 \mathrm{~mm}$. The single crack is grouted by a slurry prepared by cement, quartz sand (0.5-0.6), and water at a standard of $1: 1.5: 0.5$. By repeating this process, the single filled cracked rock samples having a crack length of $50 \mathrm{~mm}$ and $75 \mathrm{~mm}$ are made (as shown in Figure 2).

In an indoor environment, the samples are dried for 18 days and then tested. The experiments are carried out on the MTS815 system. The axial loading is controlled by displacement. The confining pressure design values are $10 \mathrm{MPa}$ and $20 \mathrm{MPa}$, and the water pressure is $7 \mathrm{MPa}$. The failure picture of the samples is shown in Figure 3.

It can be seen that under the seepage stress, the macroscopic failure mode of the single-cracked sandstone with filling material shows that the tensile cracks, which develop along the dynamic hydraulic direction, and the mixed tensile shear cracks at the distal end originate from the tensile stress concentration area near the tip of the fracture. The failure is the overall instability caused by the tensile shear mixing cracks that originate from the crack tip and extend to the upper and lower end faces of the rock sample. 


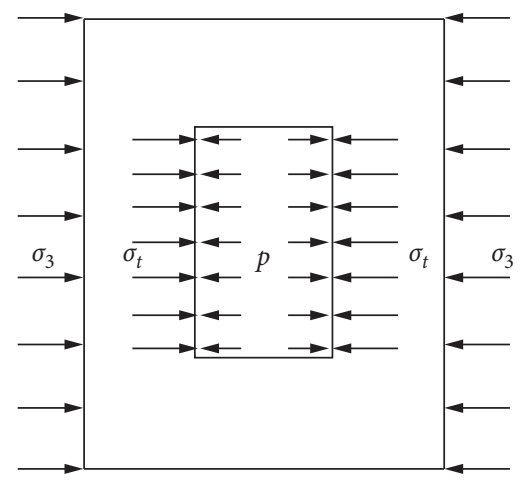

Figure 1: Mechanical model of the single-cracked rock under water pressure.

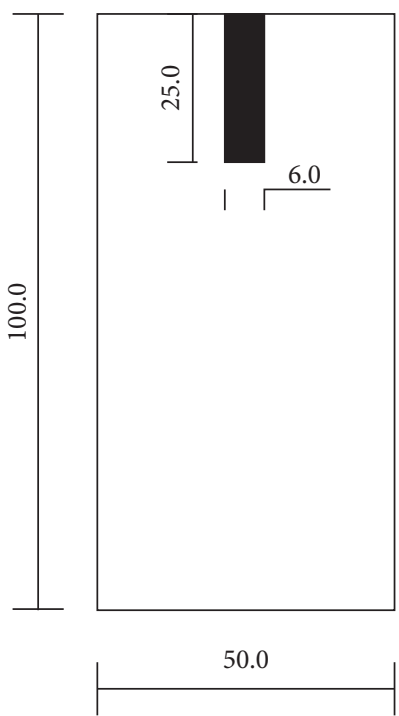

(a)

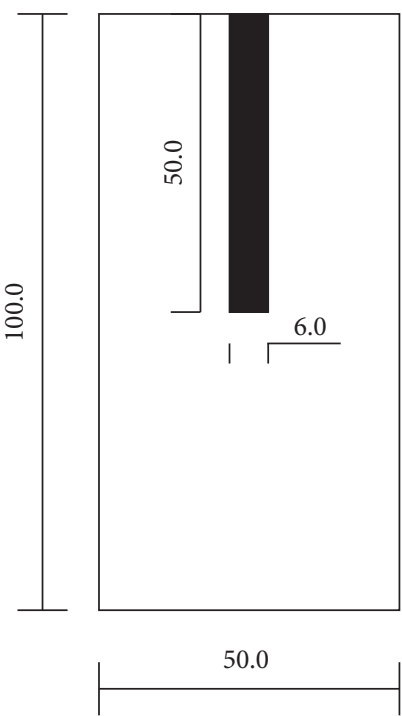

(b)

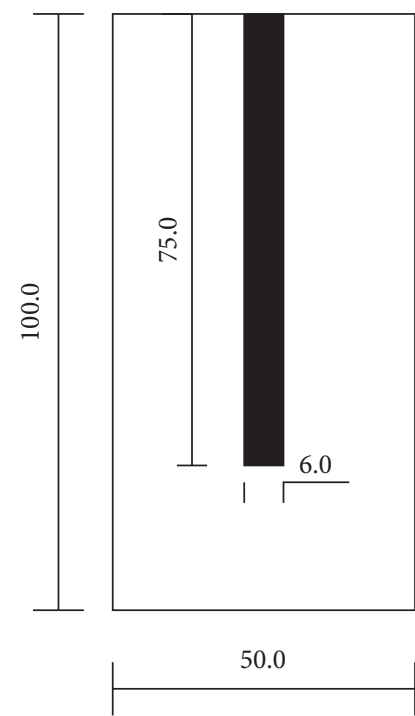

(c)

Figure 2: Schematic of three cracked rocks.

\section{Constitutive Model of Seepage Damage}

3.1. Elastic Modulus. The study of rock structure models has been carried out for a long time, and the proposed models can be roughly divided into three categories [20]. Considering the filling crack characteristics of the test rock samples, the Voigt model is used to calculate the elastic parameters of the equivalent model, as seen in Figure 4.

The model proposed by Voigt assumes that the various minerals that make up the rock are arranged in parallel along the direction of the force. The bulk modulus of each species mineral is $K_{i}$, the shear modulus is $\mu_{i}$, and the percentage of the rock volume is $V_{i}(i=1,2, \ldots, N)$. Using the volume averaging method, the multiphase equivalent rock bulk modulus $K_{V}$ of the Voigt model can be calculated as

$$
K_{V}=\sum_{i=1}^{N} K_{i} \cdot V_{i}
$$

According to the relation between the elastic parameters, the calculation equation can be written as

$$
E_{V}=3 K_{V}(1-2 v)
$$

where $E_{V}$ is the equivalent elastic modulus and $v$ is the Poisson ratio, ignoring its change with damage in this model. The calculation results are shown in Table 2.

3.2. Damage Variables and Constitutive Relations. One definition of the damage variable is a small face is taken inside the object and is evenly damaged by the $P$ force. If the total cross-sectional area of the face is $A$ and the damaged area is $A^{*}$, the net area of the surface is $\widetilde{A}=A-A^{*}$. Rabotnov [21] introduced a variable that corresponds to a continuous variable called the damage variable $D$ :

$$
D=\frac{A^{*}}{A}=\frac{A-\tilde{A}}{A},
$$

when $D=0$, it corresponds to an intact state; when $D=1$, it corresponds to a completely damaged state; when $0<D<1$, it corresponds to a different degree of the damage state. 


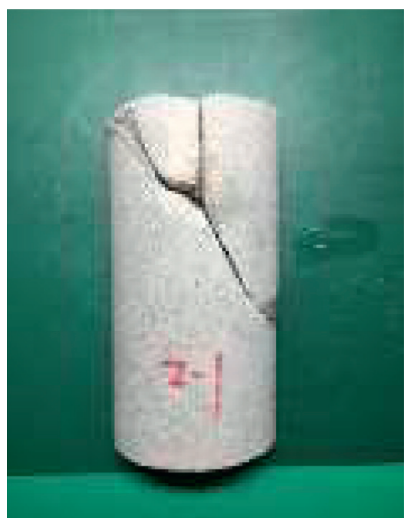

(a)

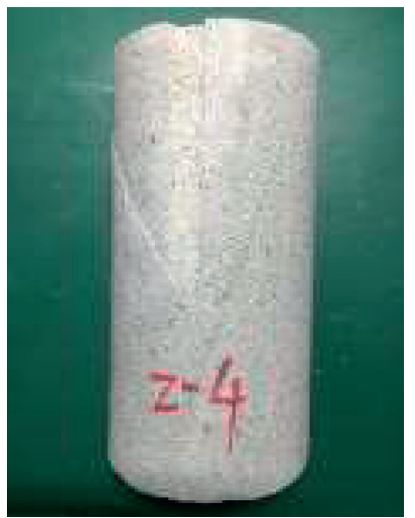

(d)

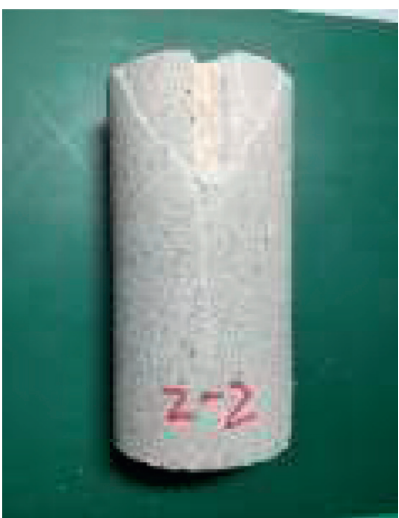

(b)

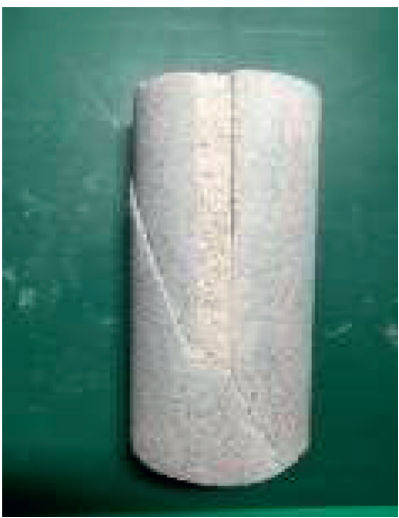

(e)

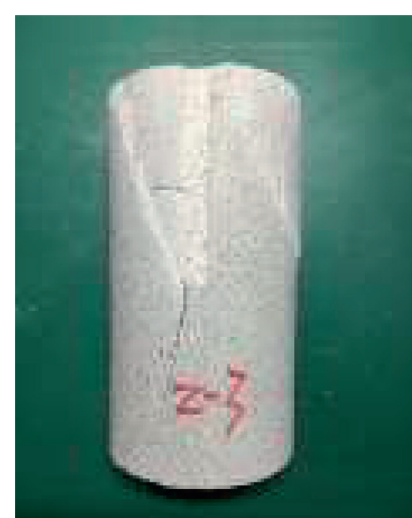

(c)

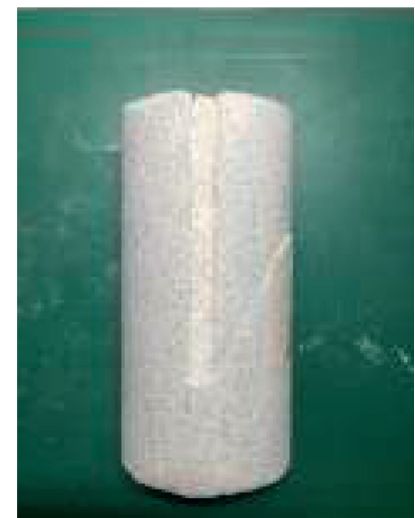

(f)

Figure 3: Failure of the cracked rock under seepage stress. (a) 2-1. (b) 2-2. (c) 2-3. (d) 2-4. (e) 2-5. (f) 2-6.

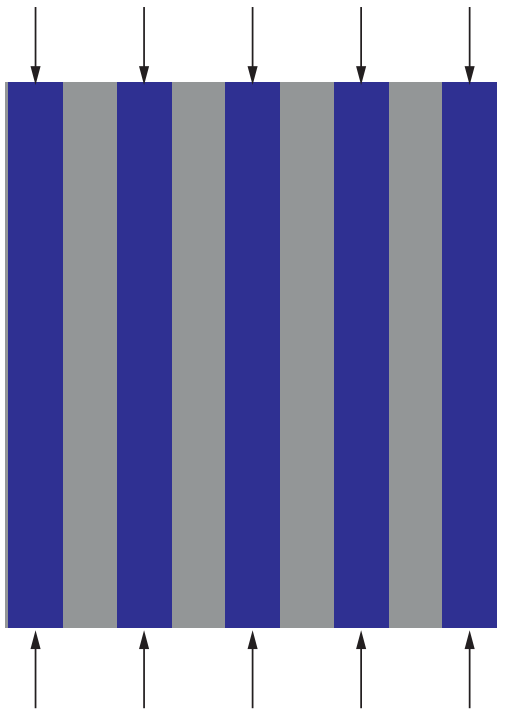

FIGURE 4: Voigt's equal strain model.

Let $\sigma=P / A$ be the nominal stress on the cross-sectional area. Let $\widetilde{\sigma}=P / \widetilde{A}$ be the stress of the net section, called the net stress. According to the principle of strain equivalence proposed by Lemaitre [22], it is assumed that the strain caused by the net stress acting on the nondestructive material is equivalent to the strain caused by the stress acting on the damaged material. The constitutive relationship of damaged materials can be obtained by nominal stress in the nondestructive material, as follows:

$$
\sigma=E \varepsilon(1-D)
$$

3.3. Rock Microunit Strength. Assuming that the rock failure criterion is

$$
f\left(\sigma^{\prime}\right)-k_{0}=0
$$

where $k_{0}$ is a constant. With the change of the stress state, if $f(\sigma \prime) \geq k_{0}$, it means that the rock microunit yields or breaks. It follows that $f(\sigma /)$ can be used as a distribution variable of rock microunit strength random distribution because it reflects the dangerous degree of rock microunit failure.

Let

$$
F=f(\sigma l)
$$

where $F$ is a distribution variable of microunit strength random distribution and $\sigma /$ is the effective stress.

The form of the rock's failure mechanism and its failure criterion entirely depends on the microunit strength form. In this paper, considering the failure mode of the cracked rock, the theory of maximum tensile strain, which is simple 
TABLE 2: The equivalent elastic parameters of the filled fractured rock.

\begin{tabular}{lcccccccc}
\hline Sample & $E_{1}(\mathrm{GPa})$ & $K_{1}(\mathrm{GPa})$ & $V_{1}(\%)$ & $E_{2}(\mathrm{GPa})$ & $K_{2}(\mathrm{GPa})$ & $V_{2}(\%)$ & $K_{V}(\mathrm{GPa})$ & $E_{V}(\mathrm{GPa})$ \\
\hline $2-1$ & 8.53 & 4.44 & 96.1 & 0.057 & 0.027 & 3.9 & 4.27 & 6.15 \\
$2-2$ & 8.88 & 4.62 & 96.1 & 0.087 & 0.041 & 3.9 & 4.44 \\
$2-3$ & 8.53 & 4.44 & 92.1 & 0.057 & 0.027 & 7.9 & 4.09 \\
$2-4$ & 8.88 & 4.62 & 92.1 & 0.087 & 0.041 & 7.9 & 4.27 \\
$2-5$ & 8.53 & 4.44 & 88.1 & 0.057 & 0.027 & 11.9 & 3.92 \\
$2-6$ & 8.88 & 4.62 & 88.1 & 0.087 & 0.041 & 11.9 & 4.07 \\
\hline
\end{tabular}

$E_{1}$ is the elastic modulus of the sandstone; $K_{1}$ is the bulk modulus of the sandstone; $V_{1}$ is the percentage of the sandstone to the sample volume; $E_{2}$ is the elastic modulus of the cement mortar; $K_{2}$ is the bulk modulus of the cement mortar; $V_{2}$ is the percentage of the cement mortar to the sample volume. The degradation of elastic modulus is not considered in this test because the MTS seepage test is to load axial stress step by step before failure, and there is no loading and unloading cycles.

and widely used in the rock media, is used to establish the rock microunit strength $F$, as follows:

$$
F=f\left(\sigma^{\prime}\right)=\sigma_{1}^{\prime}-2 \nu\left(\sigma_{2}^{\prime}+\sigma_{3}^{\prime}\right) \text {. }
$$

The effective stress principle is generally used in the analysis of stress-seepage coupling problems. Terzaghi [23] first proposed an effective stress principle adapted to onedimensional situation, and Biot [24] revised the effective stress principle and proposed a new one:

$$
\sigma_{i j}^{\prime}=\sigma_{i j}-b p_{w} \delta_{i j}
$$

where $\sigma_{i j}$ is the stress tensor, $\sigma_{i j}^{\prime}$ is the effective stress tensor, $p_{w}$ is the pore water pressure, $\delta_{i j}$ is the unit second-order tensor and $\delta_{i j}=1(i=j)$, otherwise $\delta_{i j}=0(i \neq j)$, and $b$ is the Biot coefficient and determined by the following:

$$
b=1-\frac{K}{K_{s}}
$$

where $K$ and $K_{s}$ are the bulk modulus of the solid particles and the bulk modulus of the skeleton in the rock mass. The results of the research on the Biot coefficient in the literature [25-28] indicate that the value of $b$ ranges from 0 to 1 . For most materials, the compressibility of the skeleton is much smaller than the one of the solid particles themselves, that is, $K \ll K_{s}$, so it is convenient for research to take $b=1$.

In cracked rock triaxial flow tests, assuming the rock matrix is impermeable and cracks are the seepage channel, when there is a seepage water pressure $(p=\gamma H)$ in the crack, the nominal stress $\left(\sigma_{1}, \sigma_{2}=\sigma_{3}\right)$ and strain $\left(\varepsilon_{1}\right)$ can be measured, and the corresponding effective stress is $\sigma_{1}^{\prime}, \sigma_{2}^{\prime}=\sigma_{3}^{\prime}$. tion is

According to Hooke's law and equation (7), their rela-

$$
\begin{aligned}
& \varepsilon_{1}=\frac{\left(\sigma_{1}^{\prime}-2 \nu \sigma_{3}^{\prime}\right)}{E}, \\
& \sigma_{3}^{\prime}=\sigma_{2}^{\prime}=\frac{\left(\sigma_{3}-p\right)}{(1-D)}, \\
& \sigma_{1}^{\prime}=\frac{\left(\sigma_{1}-p\right)}{(1-D)} .
\end{aligned}
$$

Substituting the above ones into equation (7) to establish the rock's microunit strength, we get

$$
F=E \varepsilon_{1} \text {. }
$$

3.4. Modified Statistical Damage Constitutive Model. This paper uses a lognormal distribution to represent the rock microunit strength:

$$
P(F)=\frac{1}{F S_{0} \sqrt{2 \pi}} \exp \left[-\frac{1}{2}\left(\frac{\ln F-F_{0}}{S_{0}}\right)^{2}\right],
$$

where $F_{0}$ and $S_{0}$ are the lognormal distribution parameters.

The number of destroyed microunits under a certain load is $N_{t}$ and the total number of microunits is $N$. The number of destroyed cells is $N P(x) \mathrm{d} x$ in any interval $[F, \mathrm{~d} F]$. When loading to a level $F$, the number of destroyed cells is

$$
N_{t}(F)=\int_{0}^{F} N P(x) \mathrm{d} x .
$$

The damage variable can be expressed as

$$
D=\frac{N_{t}}{N}=\int_{0}^{F} \frac{1}{x S_{0} \sqrt{2 \pi}} \exp \left[-\frac{1}{2}\left(\frac{\ln x-F_{0}}{S_{0}}\right)^{2}\right] \mathrm{d} x .
$$

And, it is simplified as

$$
D=\Phi\left(\frac{\ln F-F_{0}}{S_{0}}\right) \text {, }
$$

where $S_{0}$ and $F_{0}$ are the distribution parameters, $\Phi$ is a standard normal distribution function, and $\left\{\begin{array}{l}\Phi(x)=\int_{0}^{x} \varphi(s) \mathrm{d} s \\ \varphi(x)=(1 / \sqrt{2 \pi}) \exp \left(x^{2} / 2\right)\end{array},(F>0)\right.$

From equations 10-(12), the following can be obtained:

$$
\sigma_{1}=E \varepsilon_{1}(1-D)+2 \nu \sigma_{3}+(1-2 \nu) p .
$$

The damage constitutive equation obtained by substituting (17) into (18) is

$$
\sigma_{1}=E \varepsilon_{1}\left[1-\Phi\left(\frac{\ln F-F_{0}}{S_{0}}\right)\right]+2 \nu \sigma_{3}+(1-2 \nu) p
$$

According to the triaxial test process, confining pressure and pore water pressure are loaded before deviatoric stress, so that the axial strain is generated, and the strain in this 
section is not included in the test curve. The axial bias $\sigma_{1 t}$ recorded in the test is calculated as

$$
\sigma_{1 t}=\sigma_{1}-\sigma_{3}
$$

where $\sigma_{1}$ is the axial stress and $\sigma_{3}$ is the confining stress.

And, there is an initial strain $\varepsilon_{1 o}$ before the axial stress $\sigma_{1}$ is loaded, which can be calculated as follows:

$$
\varepsilon_{1 o}=\frac{1-2 \nu}{E}\left(\sigma_{3}-p\right) \text {. }
$$

So, the true axial strain $\varepsilon_{1}$ is

$$
\varepsilon_{1}=\varepsilon_{1 t}+\varepsilon_{1 o}
$$

where $\varepsilon_{1 t}$ is the measured test strain

Substituting equations (20)-(22) into equation (19), the constitutive equation of $\sigma_{1 t}$ and $\varepsilon_{1 t}$ is

$$
\begin{aligned}
\sigma_{1 t}= & {\left[E \varepsilon_{1 t}+(1-2 v)\left(\sigma_{3}-p\right)\right] \cdot\left[1-\Phi\left(\frac{\ln F-F_{0}}{S_{0}}\right)\right] } \\
& +(2 v-1)\left(\sigma_{3}-p\right) .
\end{aligned}
$$

Similarly, by substituting equations (20)-(22), equation (19) can be changed to

$$
F=\left[E \varepsilon_{1 t}+(1-2 \nu)\left(\sigma_{3}-p\right)\right] .
$$

The method of calculating the parameters of the rock damage constitutive equation is usually based on the rock triaxial stress-strain test curve using the graph method and the linear regression method. These methods have achieved good results, but the process is complicated, and it is difficult to achieve for some rocks, and the errors caused by insufficient data are large. In addition, the method of multivariate function extremum theory can be used to calculate parameters. According to the characteristic parameters of the test curve, such as peak intensity and peak strain, the parameters can be calculated. This method is not only simple, clear in physical meaning, and high in precision, but also suitable for various types of rocks.

The slope of the peak strength point $C\left(\varepsilon_{1 t c}, \sigma_{1 t c}\right)$ of the rock stress-strain test curve is 0 :

$$
\left.\frac{\partial \sigma}{\partial \varepsilon}\right|_{\varepsilon=\varepsilon_{1 t c}}=0
$$

Therefore, the result of deriving on both sides of equation (23) is

$$
\begin{aligned}
\left.\frac{\partial \sigma}{\partial \varepsilon}\right|_{\varepsilon=\varepsilon_{1 t c}}= & E\left[1-\Phi\left(\frac{\ln F-F_{0}}{S_{0}}\right)\right]-\left[E \varepsilon_{1 t}\right. \\
& \left.+(1-2 \nu)\left(\sigma_{3}-p\right)\right] \cdot P\left(F_{c}\right) \frac{\partial F}{\partial \varepsilon_{1 t}}=0,
\end{aligned}
$$

where

$$
P\left(F_{c}\right)=\frac{1}{F_{c} S_{0} \sqrt{2 \pi}} \exp \left[-\frac{1}{2}\left(\frac{\ln F_{c}-F_{0}}{S_{0}}\right)^{2}\right],
$$

and let

$$
X=\frac{\ln F_{c}-F_{0}}{S_{0}}
$$

Deformation of equation (28) can give

$$
F_{0}=X S_{0}+\ln F_{c} \text {. }
$$

The derivative result of equation (24) is

$$
\frac{\partial F}{\partial \varepsilon_{1 t}}=E
$$

Then, substituting equation (30) into equation (26), it can be obtained that

$$
P\left(F_{c}\right)=\frac{[1-\Phi(X)]}{E \varepsilon_{1 t}+(1-2 \nu)\left(\sigma_{3}-p\right)} .
$$

Substituting the peak strength point $C\left(\varepsilon_{1 t c}, \sigma_{1 t c}\right)$ into equation (23) gives the following:

$$
\begin{aligned}
\sigma_{1 t c}= & {\left[E \varepsilon_{1 t c}+(1-2 v)\left(\sigma_{3}-p\right)\right] \cdot\left[1-\Phi\left(\frac{\ln F-F_{0}}{S_{0}}\right)\right] } \\
& +(2 v-1)\left(\sigma_{3}-p\right) .
\end{aligned}
$$

Calculating equation (32), we get the following:

$$
\Phi(X)=\Phi\left(\frac{\ln F_{c}-F_{0}}{S_{0}}\right)=1-\frac{\sigma_{1 t c}-(2 \nu-1)\left(\sigma_{3}-p\right)}{E \varepsilon_{1 t c}+(1-2 \nu)\left(\sigma_{3}-p\right)} .
$$

Substituting (27) into (28), we get

$$
-\frac{1}{2} X^{2}=\ln F_{c}+\ln S_{0}+\ln \left[\sqrt{2 \pi} P\left(F_{c}\right)\right]
$$

Deforming equation (34), the result is

$$
S_{0}=\exp \left\{-\frac{1}{2} X^{2}-\ln F_{c}-\ln \left[\sqrt{2 \pi} P\left(F_{c}\right)\right]\right\} \text {. }
$$

Substituting (31 and 33) into (35), the following results are obtained:

$$
S_{0}=\exp \left\{-\frac{1}{2} X^{2}-\ln F_{c}-\ln \left[\frac{\sqrt{2 \pi}\left[\sigma_{1 t c}-(2 \nu-1)\left(\sigma_{3}-p\right)\right]}{\left[E \varepsilon_{1 t}+(1-2 \nu)\left(\sigma_{3}-p\right)\right]^{2}}\right]\right\} .
$$

So, according to the peak strength point $C\left(\varepsilon_{1 t c}, \sigma_{1 t c}\right)$ of the stress-strain curve under a confining pressure and water pressure, a $\Phi(X)$ value can be obtained by equation (33). From the normal distribution function table, the corresponding $X$ value can be found.

The parameters $F_{0}$ and $S_{0}$ can be calculated using equations (29) and (37), respectively. 


\section{Discussion}

4.1. Stress-Strain Curve. Based on the triaxial seepage tests of filled single-cracked sandstone (Table 3), the theoretical curve can be calculated by using the established constitutive model equation (23). The stress-strain model curve and the test curve of the cracked rock under seepage-stress conditions are shown in Figure 5.

It can be seen that this model has the following advantages: (1) the model can reflect the whole process of rock deformation and rupture. The model curve shows a shape consistent with the test curve, and the elastic stage of the curve agrees well, which fully reflects the evolution process of rock seepage damage. (2) It better reflects the variation of rock strength with confining pressure and crack length. The strength of rock increases with the increase in confining pressure, and it decreases with the increase in crack length. (3) From the postpeak softening stage, the damage model can also better reflect the real softening characteristics of the fractured rock after failure. (4) The model has few parameters, and the parameters are easy to calculate.

However, the model also has limitations: (1) the equivalent elastic modulus parameters used in the model cannot perfectly represent the initial compression stage of the cracked rock. Although the crack part of the rock is filled, the cement mortar still contains more pores, which makes the sample produce a larger strain during the compaction stage. Therefore, during the initial compaction stage of the filled fractured rock, the fit between the model curve and the test curve is poor. (2) The peak strength of the model curve is slightly lower than that of the test curve. In this test, the transient pulse technique is used to simultaneously test the permeability of the sample, causing the rock to creep. The viscoelastic parameters of the rock are not considered in the model, resulting in deviations in the calculated values. However, this error can be eliminated after changing the test method.

4.2. Model Verification. In order to verify the rationality of the rock damage statistical model established in this paper, the change law of the rock damage variable with strain is studied in combination with the test curve to analyze the correctness of the model damage variable (damage factor). Therefore, transforming equation (18), we can get

$$
D=\frac{\left[E \varepsilon_{1}-\sigma_{1}+2 \nu \sigma_{3}+(1-2 \nu) p\right]}{E \varepsilon_{1}} .
$$

And, substituting equations (20)-(22) into equation (36), it is obtained as

$$
D=\frac{\left(E \varepsilon_{1 t}-\sigma_{1 t}\right)}{\left[E \varepsilon_{1 t}+(1-2 \nu)\left(\sigma_{3}-p\right)\right]} .
$$

According to $\varepsilon_{1 t}$ and $\sigma_{1 t}$ values of the filled cracked sandstone obtained in the test, the corresponding damage variable $D$ can be calculated by using equation (29). Thereby, the $D-\varepsilon_{1 t}$ curve corresponding to the test curve is obtained, as shown in Figure 6.
According to the rock seepage softening damage model proposed in this paper and its parameter acquisition method, the damage factor in the model is calculated using equation (17).

The corresponding theoretical curve of $D-\varepsilon_{1 t}$ can be obtained, as shown in Figure 7.

The damage variable $D$ is a physical quantity used to measure the degree of rock damage. The damage variable evolution curve obtained from the test curve is usually $s$-type and transforms into a monotonous increase trend. The microcracks inside the rock rapidly increase in the nonlinear elastic stage within the strain range of the initial compaction stage. With the hardening of the confining pressure, the crack propagation gradually slows down to closure. After entering the linear elastic stage, the crack continuously extends to form a macroscopic crack, and the rock is cumulatively damaged and failure is at the peak strain.

However, since the elastic parameters used in the calculation model do not well characterize the deformation characteristics of the compaction stage, the damage value of the rock in the compaction stage is not reflected in the theoretical curve, and the damage value in the initial stage is zero.

Based on the results of (17) and (29), the test curves and theoretical curves of $D-\varepsilon_{1 t}$ are compared:

(1) With the increase in the axial strain, when the stress exceeds a certain level, the rock cannot bear the load and begins to produce damage. It can be seen that the peak value of the test curve and the peak value of the theoretical curve correspond to the same strain value, and the final damage variable is the same.

(2) As the confining pressure increases, the strain value increases when the rock is damaged; as the crack length increases, the strain value decreases at the same time. This rule is consistent in the test curve and the theoretical curve.

(3) In the test curve, when the axial strain is small, the change of the damage variable is not regular, and $D$ is less than 0 , which is contrary to its reasonable value interval $(0<D \leq 1)$. In the theoretical curve, when the filled fractured sandstone is subjected to a low stress level and is in a nonlinear elastic stage, the damage variable should be constant at zero. This reflects the damage threshold effect of rock material.

Therefore, the model established in this paper can reflect the characteristics of rock damage related to the stress state and can also reflect the damage state affected by the rock structural plane. The damage factor $D$ is nearly 0 in the compaction stage of the theoretical curve, which is consistent with the actual situation and more reasonable, reflecting the influence of the rock damage threshold.

Rock is a nonuniform quasibrittle material with complex mechanical properties. Considering the randomness of rock defect distribution and the nonuniformity of mechanical properties, the common research idea is to analyze the damage process by introducing statistical methods. The established statistical damage model introduces the failure 
TABLE 3: Seepage tests results of single-cracked sandstone filled with cement mortar.

\begin{tabular}{|c|c|c|c|c|c|c|}
\hline Conditions and results & $2-1$ & $2-2$ & $2-3$ & $2-4$ & $2-5$ & $2-6$ \\
\hline Sample size $(\mathrm{mm})$ & 48.57 & 48.13 & 48.31 & 48.25 & 48.26 & 48.29 \\
\hline sample size (mm) & 98.64 & 98.41 & 99.21 & 98.80 & 98.17 & 99.02 \\
\hline Crack length & $25 \%$ & $25 \%$ & $50 \%$ & $50 \%$ & $75 \%$ & $75 \%$ \\
\hline Density $\rho\left(\mathrm{g} \mathrm{cm}^{-3}\right)$ & 2.34 & 2.32 & 2.31 & 2.32 & 2.30 & 2.31 \\
\hline $\begin{array}{l}\text { Confining pressure } \\
\sigma_{3}(\mathrm{MPa})\end{array}$ & 10.00 & 20.00 & 10.00 & 20.00 & 10.00 & 20.00 \\
\hline Pore pressure (top) $(\mathrm{MPa})$ & 7.00 & 7.00 & 7.00 & 7.00 & 7.00 & 7.00 \\
\hline $\begin{array}{l}\text { Pore pressure (bottom) } \\
(\mathrm{MPa})\end{array}$ & 1.00 & 1.00 & 1.00 & 1.00 & 1.00 & 1.00 \\
\hline $\begin{array}{l}\text { Osmotic pressure difference } \\
(\mathrm{MPa})\end{array}$ & $5.38 \sim 5.93$ & $5.87 \sim 5.93$ & $5.76 \sim 5.83$ & $5.80 \sim 5.92$ & $5.76 \sim 5.87$ & $5.93 \sim 6.05$ \\
\hline Peak stress $\sigma_{1 t}(\mathrm{MPa})$ & 43.99 & 71.19 & 40.01 & 70.62 & 32.80 & 64.88 \\
\hline Peak strain & 0.0081 & 0.0098 & 0.0067 & 0.0090 & 0.0054 & 0.0097 \\
\hline $\begin{array}{l}\text { Permeability (Darcy) } \\
(\nu=0.20)\end{array}$ & $7.94 \sim 8.67$ & $3.51 \sim 3.64$ & $8.35 \sim 9.84$ & $4.72 \sim 4.90$ & $11.62 \sim 11.85$ & $5.85 \sim 6.06$ \\
\hline
\end{tabular}
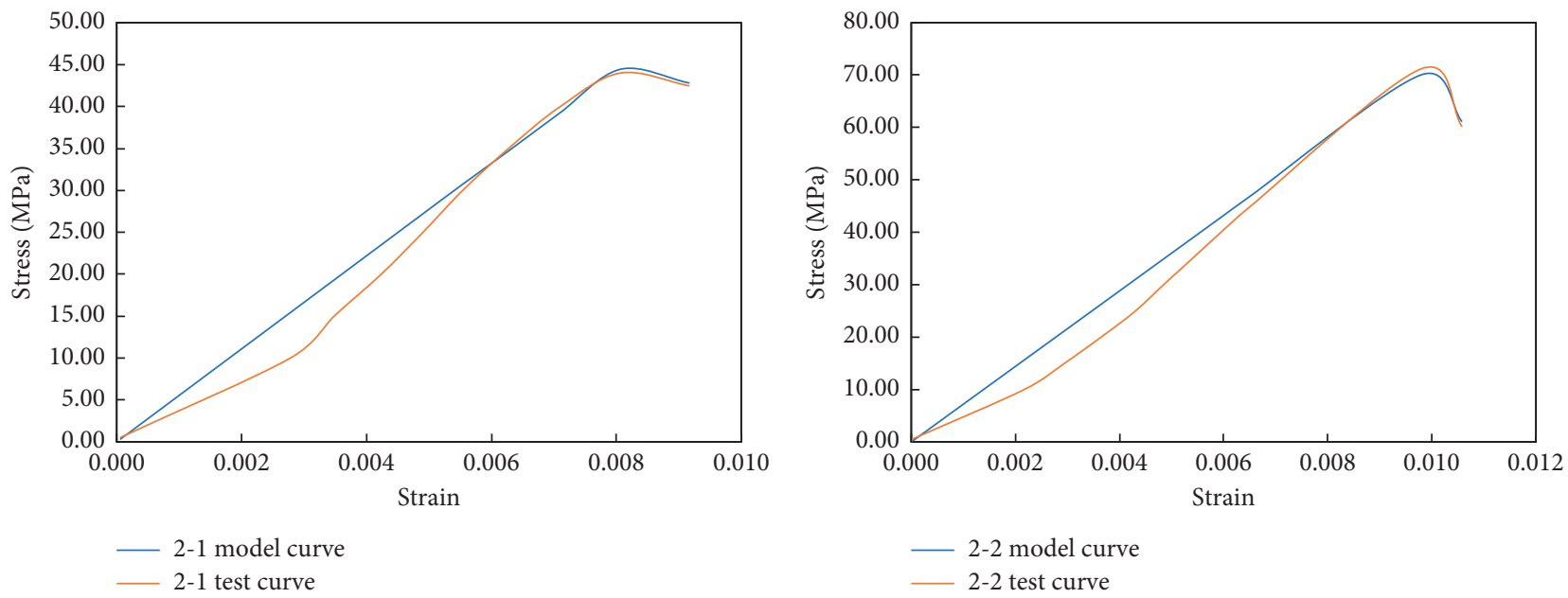

(a)

(b)
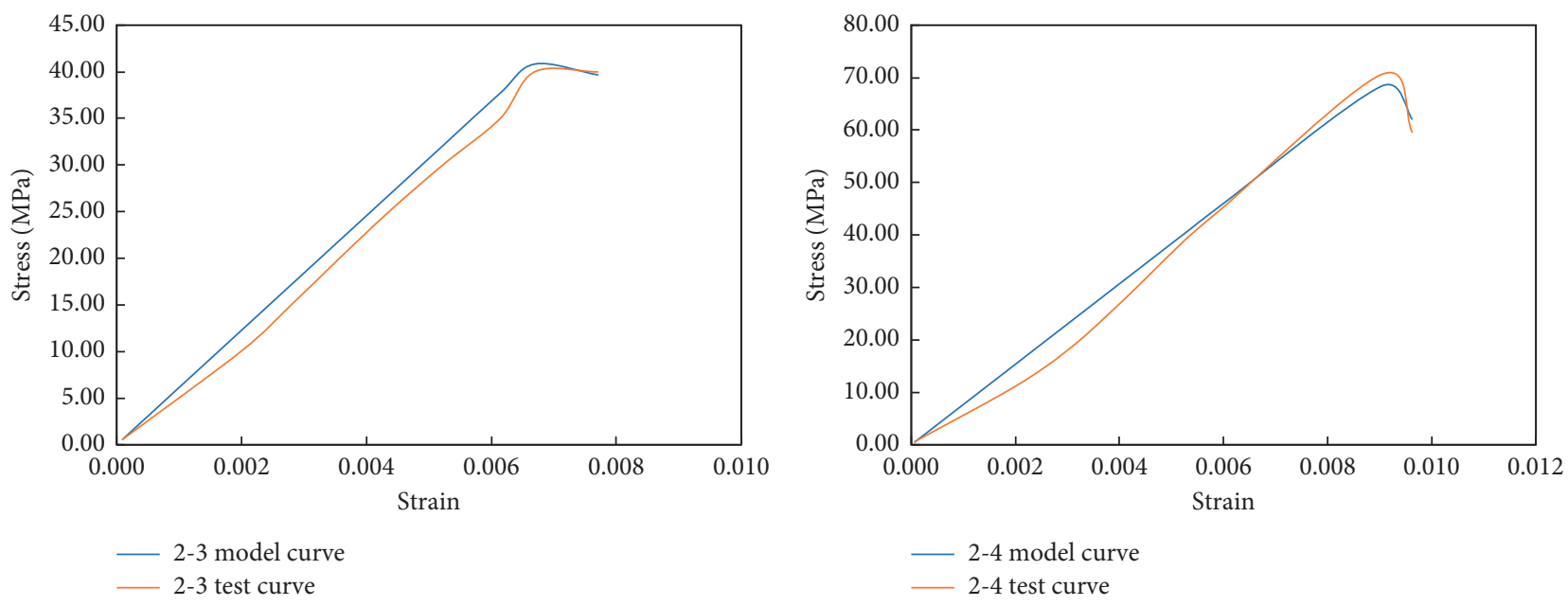

(c)

(d)

Figure 5: Continued. 


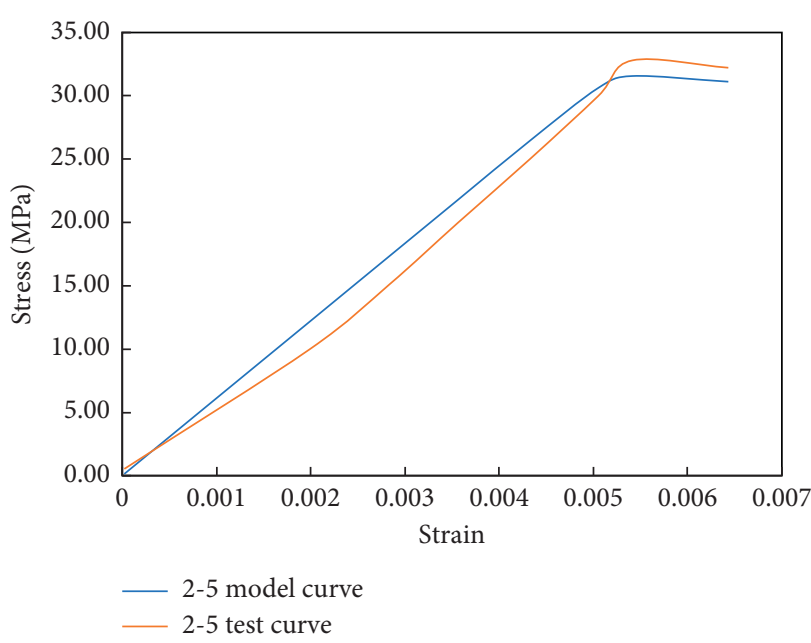

(e)

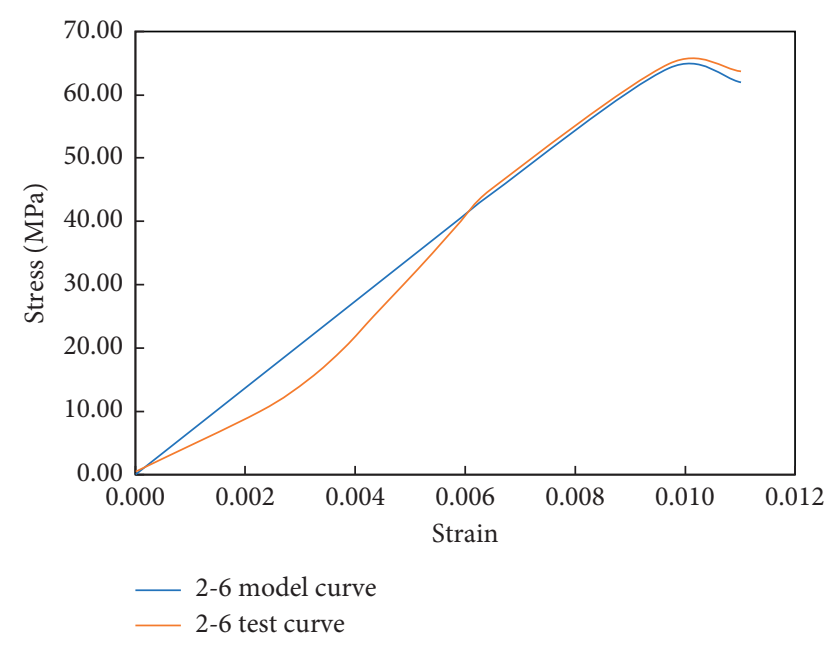

(f)

FIGURE 5: Stress-strain model curve and the test curve of the cracked rock. (a) 2-1. (b) 2-2. (c) 2-3. (d) 2-4. (e) 2-5. (f) 2-6.

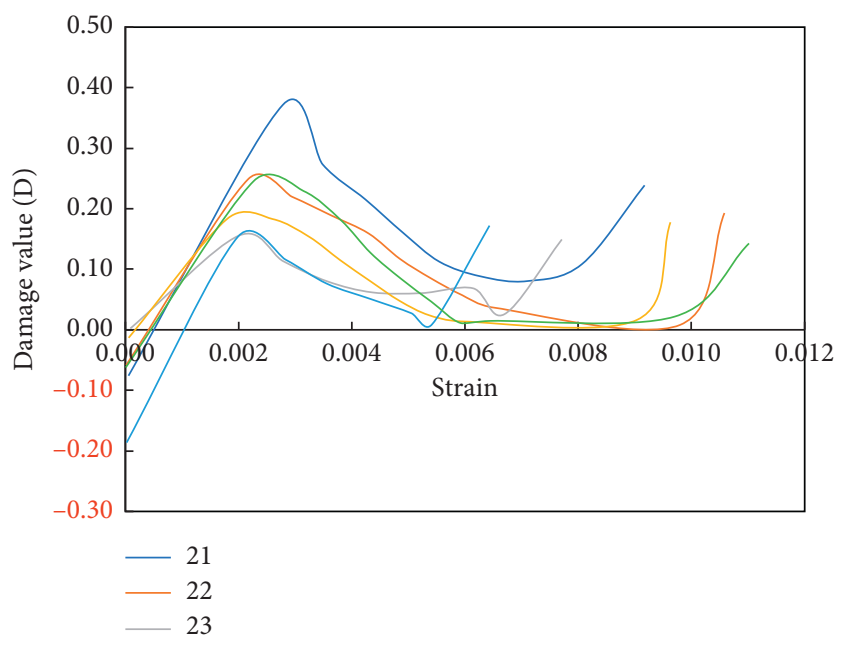

Figure 6: $D-\varepsilon_{1 t}$ test curve.

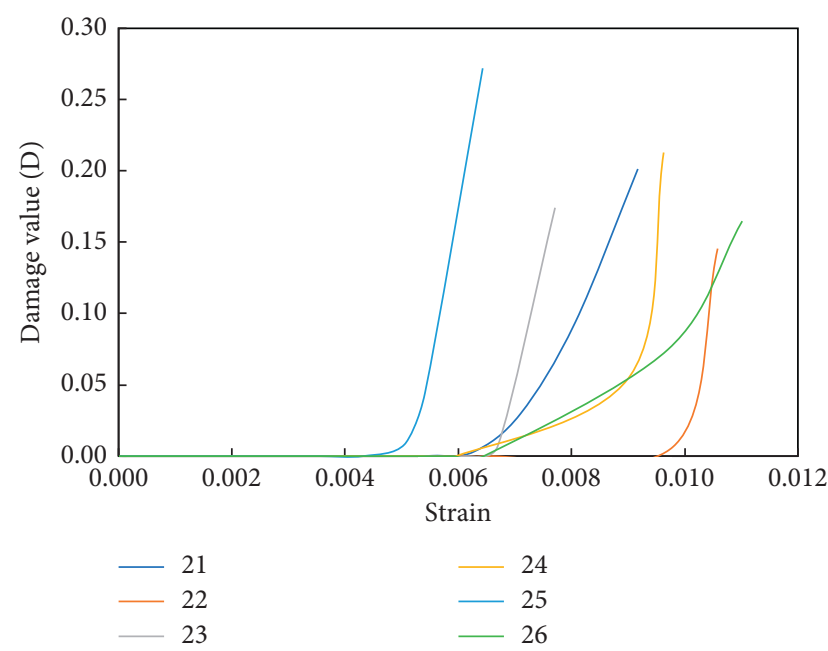

FIGURE 7: $D-\varepsilon_{1 t}$ theoretical curve. criterion as a physical mechanic parameter into the nonuniformity of the material through a random distribution function. Lognormal distribution is widely used as the structural resistance probability distribution in structural reliability theory, and it can be considered that the random distribution of rock mechanical property parameters is similar to the resistance distribution of structural members. In describing the rock damage deformation curve, the lognormal model curve is more in line with the actual situation, and the curve shape and the final value are more accurate in this paper.

However, in geotechnical engineering, the types of filling in cracked rocks are very rich, such as hydraulic materials that can still play the role of bonding and strength in water like cement mortar, and there are also air-hardening materials that lose their cohesiveness and strength when encountering water. There are self-weight fillings as in this paper's experiment, and there are also pressure cement fillings. At the same time, the fracture types of rock mass are more diverse, such as single fracture, multifractures, and en echelon joints. This study only reflects the applicability of the established lognormal statistical damage model in describing the seepage mechanical properties of single-fractured sandstone filled with cement mortar, which has little limitations in the experimental design and result data. In the future work, we will consider conducting more experimental studies on the seepage mechanical properties of fractured rocks with different fillings and fracture types under different stress environments to learn more about the applicability of the lognormal distribution statistical model.

\section{Conclusion}

In this paper, the permeability test of the fractured sandstone filled with cement mortar at a confining pressure of $20 \mathrm{MPa}$ and $10 \mathrm{MPa}$ and the water pressure at $7 \mathrm{MPa}$ is completed. According to the tests data, the lognormal distribution is 
used as a probability distribution model of rock microunit strength to establish a rock stress-strain relationship constitutive model. According to the failure characteristics of the fractured rock in the seepage-stress field, the strength of the rock microunit is determined based on the maximum tensile strain failure criterion. And, considering the influence of confining pressure and water pressure, Hooke's law and the effective stress principle are used to improve the model parameter. The equivalent elastic modulus of the filled fractured rock is calculated by Voigt's space average model. Finally, a statistical constitutive model of the lognormal distribution of seepage damage in the fractured rock is established. The following conclusions can be drawn:

(1) The established rock damage statistical model agrees well with the experimental curve and can better reflect the stress-strain relationship of the filling fracture rock under different external load conditions and different structural plane types.

(2) This model can fully reflect the characteristics of rock damage related to the stress state and also reflect the damage state affected by the characteristics of the rock structural plane.

(3) The damage peak of the model curve is consistent with the actual situation, and its initial damage strain reflects the rock damage threshold effect, so the model is reasonable and meaningful.

(4) This model has few parameters, simple acquisition, and clear physical meaning, which is extremely convenient in engineering application.

\section{Data Availability}

Demand data used to support the findings of this study are available from the first author upon request.

\section{Conflicts of Interest}

The authors declare that there are no conflicts of interest regarding the publication of this paper.

\section{Acknowledgments}

This study was supported by the National Natural Science Funds (41831278 and 51878249) of China, the Guangdong Province Water Resource Science and Technology Innovation Program (2017-30) of China, and the Postgraduate Research and Practice Innovation Program of Jiangsu Province (2018B661X14).

\section{References}

[1] J. W. Dougill, J. C. Lau, and N. J. Burt, Toward a Theoretical Model for Progressive Failure and Softening in Rock, University of Waterloo Press, New York, NY, USA, 1976.

[2] W. Weibull, "A statistical theory of the strength of materials," Proceedings of the American Mathematical Society, vol. 151, no. 5, p. 1034, 1939.
[3] D. Krajcinovic and M. A. G. Silva, "Statistical aspects of the continuous damage theory," International Journal of Solids and Structures, vol. 18, no. 7, pp. 551-562, 1982.

[4] W. Cao, H. Zhao, Li Xiang, and L. Zhang, "A statistical damage simulation method for rock full deformation process with consideration of the deformation characteristics of residual strength phase," China Civil Engineering Journal, vol. 45, no. 6, pp. 139-145, 2012.

[5] S. Chen, C. Qiao, Q. Ye et al., "Comparative study on threedimensional statistical damage constitutive modified model of rock based on power function and Weibull distribution," Environmental Earth Sciences, vol. 77, no. 3, p. 108, 2018.

[6] W.-g. Cao, X. Li, and H. Zhao, "Damage constitutive model for strain-softening rock based on normal distribution and its parameter determination," Journal of Central South University of Technology, vol. 14, no. 5, pp. 719-724, 2007.

[7] S. Yang, W. Xu, W. Lide et al., "Statistical constitutive model for rock damage under uniaxial compression and its experimental study," Journal of Hohai University (Natural Sciences), vol. 32, no. 2, pp. 200-203, 2004.

[8] S. Cao, P. Guo, Y. Liu et al., "Development of cracks in the process of coal destruction," Journal of China University of Ming \& Technology, vol. 42, no. 5, pp. 725-730, 2013.

[9] Z. Zhu, Q. Huang, J. Wang et al., "Mesoscopic experiment on degradation evolution of rock deformation and its mesodamage mechanical mode," Chinese Journal of Rock Mechanics and Engineering, vol. 32, no. 6, pp. 1167-1175, 2013.

[10] Y. Wang, X. Li, Y. F. Wu, C. Lin, and B. Zhang, "Experimental study on meso-damage cracking characteristics of RSA by CT test," Environmental Earth Sciences, vol. 73, no. 9, pp. 55455558, 2015.

[11] X. F. Li, H. B. Li, L. W. Liu et al., "Investigating the crack initiation and propagation mechanism in brittle rocks using grain-based finite-discrete element method," International Journal of Rock Mechanics and Mining Sciences, vol. 127, no. 3, pp. 1-20, 2020.

[12] X. F. Li, Q. B. Zhang, H. B. Li et al., "Grain-based discrete element method (GB-DEM) modelling of multi-scale fracturing in rocks under dynamic loading," Rock Mechanics \& Rock Engineering, vol. 51, no. 8, pp. 3785-3817, 2018.

[13] X. F. Li, H. B. Li, and J. Zhao, "3D polycrystalline discrete element method (3PDEM) for simulation of crack initiation and propagation in granular rock," Computers and Geotechnics, vol. 90, no. 10, pp. 96-112, 2017.

[14] X. F. Li, H. B. Li, and J. Zhao, "The role of transgranular capability in grain-based modelling of crystalline rocks," Computers and Geotechnics, vol. 110, no. 6, pp. 161-183, 2019.

[15] Z. P. Bazant, "Size effect," International Journal of Solids and Structures, vol. 37, no. 1, pp. 69-80, 2000.

[16] L. Chen, Z. Chen, and J. Liu, "Probability distribution of soil strength," Rock and Soil Mechanics, vol. 26, no. 1, pp. 37-40, 2005.

[17] M. Zhang, Z. Li, and X. Su, "Probabilistic volume element modeling in elastic damage analysis of quasi-brittle materials," Chinese Journal of Rock Mechanics and Engineering, vol. 24, no. 23, pp. 4282-4288, 2005.

[18] F. Zeng, F. Peng, and J. Guo, Gas Mass Transport Model for Micro Fractures Considering the Dynamic Variation of Width in Shale Reservoirs, pp. 1265-1281, SPE Reservoir Evaluation \& Engineering, Anhui, China, 2019.

[19] Z. Rui, T. Guo, Q. Feng, Z. Qu, N. Qi, and F. Gong, "Influence of Gravel on the propagation pattern of hydraulic fracture in 
the Glutenite Reservoir," Journal of Petroleum Science and Engineering, vol. 165, no. 6, pp. 627-639, 2018.

[20] Y. Chen, T. Huang, and E. Liu, Rock Physics, Press of USTC, Anhui, China, 2009.

[21] N. Y. Rabotnov, "On the equation of state of creep," $A R$ CHIVE: Proceedings of the Institution of Mechanical Engineers, vol. 178 , no. 3, pp. 117-122, 1963.

[22] J. Lemaitre, "A continuous damage mechanics model for ductile fracture," Journal of Engineering Materials and Technology, vol. 107, no. 1, pp. 83-89, 1985.

[23] K. Terzaghi, "The shearing resistance of saturated soils and the angle between the planes of shear," in Proceedings of the 1st International Conference of Soil Mechanics and Foundation Engineering, pp. 54-56, Cambridge, England, 1936.

[24] M. A. Biot, "General theory of three-dimensional consolidation," Journal of Applied Physics, vol. 12, no. 2, pp. 155-164, 1941.

[25] R. L. Kranz, A. D. Frankel, T. Engelder, and C. H. Scholz, "The permeability of whole and jointed Barre Granite," International Journal of Rock Mechanics and Mining Science \& Geomechanics Abstracts, vol. 16, no. 4, pp. 225-234, 1979.

[26] J. B. Walsh, "Effect of pore pressure and confining pressure on fracture permeability," International Journal of Rock Mechanics and Mining Sciences \& Geomechanics Abstracts, vol. 18, no. 5, pp. 429-435, 1981.

[27] D. Hu, H. Zhou, P. Pan et al., "Study of permeability of sandstone in triaxial cyclic stress tests," Rock and Soil Mechanics, vol. 31, no. 9, pp. 2749-2754, 2010.

[28] Y. Lu and H. Sun, "Investigation on mechanical parameters of water-rock interaction," Chinese Journal of Rock Mechanics and Engineering, vol. 28, no. 10, pp. 1995-2005, 2009. 